Sultan Qaboos University Journal of Arts \& Social Sciences
جامعة السلطان قابوس

مجلة الآداب والعلوم الاجتمأعية

\title{
Benchmarking the hotel industry in Oman through a three-stage DEA-based procedure
}

\author{
Amar Oukil \\ Assistant Professor \\ Department of Operations Management \& \\ Business Statistics, \\ College of Economics \& Political Science \\ Sultan Qaboos University \\ aoukil@squ.edu.om
}

\begin{tabular}{c}
\hline Asma Al-Zidi \\
\hline Assistant Professor \\
Department of Operations Management \& \\
Business Statistics, \\
College of Economics \& Political Science \\
Sultan Qaboos University \\
alzidia@squ.edu.om
\end{tabular}




\title{
Benchmarking the hotel industry in Oman through a three-stage DEA-based procedure
}

\author{
Amar Oukil and Asma Al-Zidi
}

Abstract:

This study is concerned with benchmarking the hotel industry in the Sultanate of Oman besides identifying the environmental factors that influence the operational efficiency of hotels. The benchmarking analysis is carried out through data envelopment analysis (DEA), used essentially to evaluate the efficiency ratios of a selected sample of 58 hotels. Although less than $23 \%$ of the hotels are found efficient, the average efficiency score of $83 \%$ indicates a reasonable efficiency in resource management for most of the hotels. Regarding the contextual effects, hotel Size, Star rating and cultural attractions are found to have the most significant effect on hotel efficiency in Oman. The positive effect of cultural attractions can inform policy makers on the necessity to preserve and promote cultural heritage as an important key factor of attraction.

Keywords: Hospitality management, Performance, Data Envelopment Analysis (DEA), Integrated stochastic model; Oman.

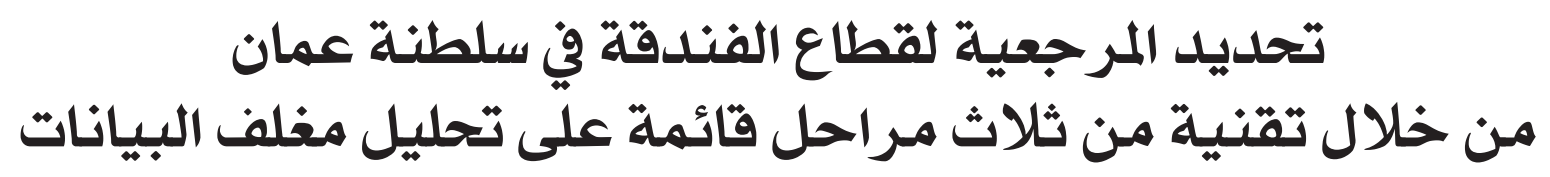

عمَّار أوكيل وأسماء الزَّيدي

\footnotetext{
الملخص:

الهدف من هذه الدراسة هو تقييه قطاع الفنادق في سلطنة عمان و تحديد العوامل البيئية التي تؤثر على الكفاءة التشغيلية لهذه الفنادق.

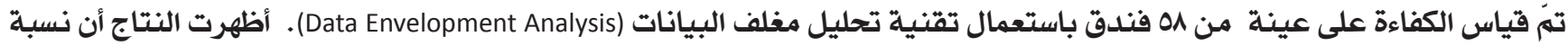

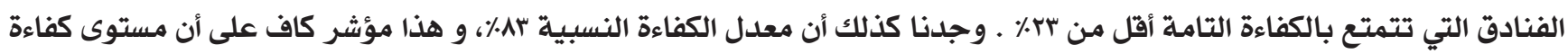
القطاع الفندقي مقبول نسبيا من حيث إدارة الموارد. من جانب آخر، بينت الدراسة أن حجم الفندق (عدد الغرف)، عدد النجوم و كذا

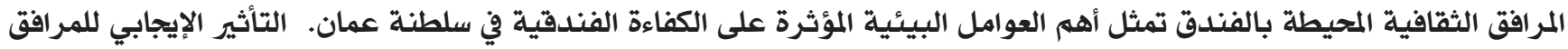
الثقافية يمكن أن يعزز القرارات المؤسساتية المتعلقة بمضاعفة الجهود لصيانة التزاث الثقافي وتعزيز مرافقه. 


\section{Introduction:}

Nowadays, tourism has become a key source for foreign incomes, driving the whole industry into fierce worldwide competition, especially the lodging sector (Chin et al., 2013). Hotels must compete globally to attract customers whilst obligated to achieve high profits (Tarim et al., 2000), because a hotel that is less efficient than its competitors can barely survive on the market (Barros et al., 2011). Achieving efficiency requires the identification of resources that can be cut while keeping returns unchanged. As a result, hotel rooms can be sold at lower prices, enhancing "price" as a key competitive priority. Viewed from this perspective, efficiency analysis becomes essential to developing a meaningful set of benchmarks that dictate best practices and form a successful hotel business model (Min et al., 2009a).

The measurement of efficiency in the hotel industry was a focus of attention of several studies up to late 1990s, but it has gained renewed attention over the last decade, due probably to the development of new empirical techniques (Barros, 2005a). Early studies on hotel's efficiency employed performance indicators, such as yield management (Donaghy et al., 1995; Kimes 1989), aggregate indices (Wassenaar and Stafford, 1991) and breakeven analysis (Wijeysinghe, 1993). Yet, these approaches remain partial indicators, often inadequate for an accurate analysis of potential efficiency gains (Anderson et al., 2000; Barros et al., 2009). The main downsides of such analyses dwells in their inability to adequately estimate overall performance measures, identify benchmarking policies, and analyze the effects of economies of scale (Wu et al., 2007). To remedy these deficiencies, frontier efficiency methods are introduced, namely, the stochastic frontier (Greene, 2008) and data envelopment analysis (Cooper et al., 2002). The stochastic frontier analysis (SFA) requires the output of the decision making units (DMUs) to be expressed through an explicit functional form in terms of a set of inputs, an inefficiency factor, and a random error with a distribution assumed a priori (Coelli et al., 2005). In the hotel industry, some leading studies that use SFA include Anderson et al. (1999), Barros (2004), Barros (2006), Chen (2007), and Hu et al. (2010). Unlike the SFA, data envelopment analysis (DEA) is a nonparametric approach that does not impose functional forms on the data, nor does it need to use probability distributions (Barros et al., 2011). Furthermore, DEA has the potentials to evaluate the efficiency of DMUs that employ multiple inputs (resources) to produce multiple outputs (products and/or services).

According to Wöber (2007), efficient frontier methods have been widely used in the past, but "it has been just recently that tourism researchers have discovered $D E A$ for examining efficiency in their industry". Indeed, banking, healthcare, agriculture, transportation, and education are the most popular application areas of DEA. Liu et al. (2013) point out that these areas make up $41 \%$ of all DEA application papers while the share of tourism is estimated to only $1.34 \%$. Wöber (2002) confirms that Hruschka (1986) and Banker and Morey (1986a) were the first to apply DEA to hospitality industry, more specifically, to restaurants. Later, Bell and Morey $(1994,1995)$ used DEA to determine the best practices in corporate travel agencies.

The application of DEA to the hotel industry is pioneered by Morey and Dittman (1995). Over 63\% of the publications we surveyed cover destinations in the Asian Pacific region (Keh et al., 2006; Assaf, 2012). Around $50 \%$ of the papers deal only with cases in Taiwan (e.g., Huang et al., 2014; Assaf et al., 2010; Chen, 2009, 2011; Chin et al., 2013; Chiu and Huang, 2011; Hsieh et al., 2010; Lin et al., 2012; Shang et al., 2008; Shyu and Hung, 2012; and Wang et al., 2006). China follows with the work of Zhou et al. (2008), Tsai (2009), Zhang and Ma (2011), and Huang et al. (2012). Cases in South-Korea are discussed by Hokey et al. (2008), Min et al. (2009a, 2009b). There is only one case addressed in other countries, like Australia (Avkiran, 2002), India (Sanjeev, 2007), Japan (Honma and $\mathrm{Hu}, 2012$ ), Singapore (Ashrafi et al., 2013), and Malaysia (Rahmati \& Jalil, 2014). Studies related to the industry in the United States include Morey and Dittman (1995, 2003), Anderson et al. (2000), Brown and Ragsdale (2002), and Hu and Cai (2004). In Europe, Portugal has the highest share (e.g., Barros and Alves, 2004; Barros, 2005a, 2005b; Barros and Mascarenhas, 2005; Barros and Santos, 2006; Barros et al., 2009, 2011; Oliveira et al., 2013), preceding the United Kingdom (e.g., Johns et al., 1997; Sigala, 2004; Sigala et al., 2004; Sigala et al., 2005), France (e.g., Botti et al., 2009; Perrigot et al., 2009), Italy (e.g., Pulina et al., 2010; Tundis et al., 2012), Greece (Manasakis et al., 
2013), Spain (Fernández and Becerra, 2013), and Slovenia (Assaf and Cvelbar, 2010). In Africa, performance analyses employing DEA are found for Angola (Barros and Dieke, 2008), Tanzania (Sharma and Sneed, 2008) and Tunisia (Hathroubi et al., 2014). DEA-based research on the hotel industry's performance in the Middle East is very scarce. The few existing publications that have been surveyed consider cases in Turkey (e.g., Tarim et al., 2000; Önüt and Soner, 2006; Tumer, 2010), Iran (Shirouyehzad et al., 2012) and Israël (Hadad et al., 2005). Apart from the study of Assaf and Barros (2011) which involves Saudi Arabia (KSA), the United Arab Emirates (UAE) and Oman as a block, there is no known research dedicated to a specific country of the Gulf region. Therefore, conducting such a study in Oman stems primarily from a gap that needs to be filled in the literature alongside the importance of Oman as a major touristic and economic destination in the Gulf region, as well as an excellent location for investments (Assaf and Barros, 2011).

With these objectives in mind, the present study aims to provide efficiency measures and identify potential sources of inefficiency through a two-stage approach (Barros et al., 2011; Shang et al., 2010). The approach starts with a DEA evaluation of each hotel's technical efficiency using endogenous variables, i.e. variables that are under the control of decision makers over the time period of consideration. In the second stage, these efficiency scores are regressed over a set of exogenous factors that are neither inputs nor outputs, but can still influence the operating process (Jeong et al., 2010). The objective of the second stage is to detect, among these factors, those that contribute most significantly to the efficiency of the hotels.

A large number of topical papers, including Hoff (2007), McDonald (2009), and Ramalho et al. (2010), argue that the second stage should use either loglinear or Tobit models. Using empirical results, these models might fail to discriminate the most influential contextual factors. Building on related theory, we develop a methodology to circumvent such a hindrance.

The contribution of the present study to the hospitality and tourism literature is four-fold. First, the study researches efficiency measures of the Omani hotel industry, a topic that has not been addressed yet, in spite of its pertinence to such a growing industry. Second, the study examines the contextual factors that impact the hotel industry in Oman as well as in other tourism destinations with similar characteristics. A new methodology is developed not only to identify these factors, but also to assess the consistency of DEA decisions. Last, an empirical approach is introduced to quantify the attractiveness of touristic destinations.

The remainder of the paper unfolds as follows. In the next section, we present a brief review of the literature pertaining to the two-stage approach in the hotel industry. In Section 3, we describe the application context and stress the importance of the current study. In Section 4, we explain our methodology and define related efficiency measures, including aggregate, technical and scale efficiencies. Section 5 discusses the conceptual model as well as the choice of input and output variables. Section 6 is dedicated to the application of DEA models and discussion of the findings. In the next section, we conduct an econometric analysis to establish potential correlation between the hotel contextual factors and efficiency levels. We conclude with recommendations and possible venues for future research.

The two-stage approach in the hotel industry:

A review:

In the literature of performance analysis, several studies have provided updated reviews of the application of data envelopment analysis (DEA) in the hospitality industry (see, e.g., Manasakis et al., 2013, Shyu \& Hung, 2012). The application of the two-stage approach in the hotel industry is quite recent. In Hu et al. (2009), DEA is adopted to evaluate the operational performance of international tourist hotels (ITHs) in Taiwan during 1997-2006, prior to a regression of the efficiency ratios on a set of environmental variables using Tobit model. Within the same context, Chen et al. (2010) estimate the cost efficiency scores of the ITHs before applying the Tobit approach. The latter approach is also adopted in Honma and Hu (2012), where DEA and SFA are first used to assess performance of 15 Japan's major hotel companies.

Barros et al. (2011) use CCR (Charnes, Cooper, and Rhodes, 1978) model to estimate technical efficiency of 21 Portuguese hotels, and a truncated regression analysis (Simar and Wilson, 2007) is carried out to determine the drivers of efficiency. Tundis et al. (2012) employ a similar approach to gauge the explanatory power of a large set of management and entrepreneurial variables. Meanwhile, CCR model is 
used jointly with the approach of Sampaio de Souza and Stosic (2005) to screen outliers out of the initial dataset before calculating the final efficiency. The truncated regression model is also used to investigate the effect of regional environmental quality (Chen et al., 2014) or traffic convenience and medical services (Hu et al., 2014) on the cost efficiency of hotels in Taiwan. Hathroubi et al. (2014) adopt similar approach to analyze the influence of environmental attributes on hotels' technical efficiency in Tunisia.

Huang et al. (2012) use data envelopment window analysis through years 2001-2006 to identify general trends of efficiency and individual patterns of relative efficiency variation of 31 regional hotel sectors in China. The impact of macro contextual variables on technical efficiency over the time horizon is investigated via a dynamic Tobit model that incorporates the historical average technical efficiency score as an explicative variable. Oliveira et al. (2013) apply a two-stage approach to investigate the influence of star ratings, golf courses and location on the efficiency of a sample of 84 hotels in Portugal. First, CCR and BCC (Banker, Charnes, and Cooper, 1984) models are used to evaluate the efficiency of each hotel. In the second stage, a statistical test (Carvalho and Marques, 2011) is applied to conclude that hotels without golf courses are more efficient than their counterparts.

In line with previous research, we adopt Tobit and loglinear models for the second-stage, and we show that these models, although widely applied in the literature, may statistically fail to support any plausible decision. As an alternative, we develop a stochastic model that gauges potential influence of environmental factors on efficiency evaluation and appraises the consistency of the DEA decisions.

\section{Contextual setting:}

The sultanate of Oman is located on the southern tip of the Arabian Peninsula with, on its borders, the UAE, KSA and Yemen. Oman covers an area of $309,500 \mathrm{~km}^{2}$, with rugged mountains and rocky deep-water fjords to the north, the mountains and green hills of the Dhofar region to the south, and the Wahiba Sands in the center (Choufany and Younes, 2005). Lying on the Tropic of Cancer, Oman is one of the world's hot, arid regions though part of the south of the country has a tropical climate (Figure 1).
insertOman's economy is oil based, with an oil activity accounting for $35 \%$ of Gross Domestic Product (GDP) (ithraa, 2016). Oman has been successful at turning its oil wealth into broad-based economic growth, stirred by the government's strategy of diversifying the economy and reducing dependence on petroleum resources. Although the latest among the Gulf countries to join the tourism "race", Oman is emerging as one of the most attractive tourism destinations on the Arabian Peninsula with the number of tourists increasing every year (Winckler, 2007). As such, tourism industry is perceived among the key alternatives to petroleum based economy (Subramoniam et al., 2010) and set as one of the top targets of the long-term socio-economic plan, namely, "Oman 2020" (Winckler, 2007). According to data from the World Travel \& Tourism Council (WTTC), the industry's total contribution to GDP nears 5.7\% in 2015 with 111,500 jobs, equivalent to $5.7 \%$ of total employment (WTTC, 2016). The same source predicts a figure of $7.7 \%$ contribution to GDP by 2026 with 164,000 jobs representing $7.9 \%$ of total employment.

The statistics of the Ministry of Tourism reveal that there are 315 hotels in Oman, accounting for 16,691 rooms, with 128 hotels in the capital Muscat alone. The ministry also expects 10,000 additional hotel rooms, including those from luxury resorts to budget hotels, by 2018. Much of this additional capacity consists of resort-style complexes outside the capital, both on the Arabian Sea and Gulf of Oman coasts. With a sector expanding so rapidly, policy makers as well as private investors need tools that would grip as intimately as possible the dynamics of the hospitality market to support their decisions. Here, performance analysis of the hotel industry becomes an imperative.

\section{Methodological framework:}

Our methodological approach deploys over twostages. The first stage uses DEA to estimate the hotels' efficiency scores. In the second stage, an econometric analysis is conducted to discern possible correlation between technical efficiency and the contextual factors. The latter factors, also known as environmental, exogenous, or non-discretionary variables (Fried et al., 2002), are not easy to control, though potentially influencing the efficiency (Shang et al., 2010).

Data envelopment analysis (DEA) is a non-parametric approach that employs linear programming (LP) to 
construct a production technology frontier out of the fully efficient DMUs, and relative efficiencies of all DMUs are evaluated in relation to the estimated frontier.

The DEA models that are most frequently applied in the hotel industry are CCR (Charnes et al., 1978), which assumes constant returns to scale (CRS), and BCC (Banker et al., 1984), which allows variable returns to scale (VRS). VRS implies disproportionate variation in outputs when inputs are increased. Under either CRS or VRS assumption, the managerial purposes of efficiency analysis, in a competitive context, are the measurement of relative efficiency ratios as an essential step to setting industry's benchmarks, besides the estimation of allowable reductions of the inputs consumed by inefficient DMUs. Resource reduction enables hotels to achieve cost savings which, in turn, provide flexibility to lower room prices and be more competitive on the market. Therefore, the input-oriented versions of CCR and BCC models are more suitable to pinpoint resources that can be reduced without altering the outputs (Oliveira et al., 2013). Other models are used in the literature, depending on the contexts and managerial objectives. Recent reviews and references can be found in Manasakis et al. (2013) and Shyu and Hung (2012).

\section{CCR and BCC input-oriented models:}

Assume a set of $K$ hotels, each hotel $k$ defined with $N$ inputs $x$ and $M$ outputs $y$. With reference to the underlying production technology, hotel $\left(x_{k}, y_{k}\right)$ is fully defined with the observed values $x_{i k}$ and $y_{j k}$, with $i=1, . ., N$ and $j=1, . ., M$. To estimate the efficiency score $\theta$ of hotel $\left(x_{0}, y_{0}\right)$ and set production targets for inefficient hotels, the input-oriented formulation of CCR model can be represented as follows.

$\min \theta$

Subjectto :

$$
\begin{array}{rl}
\sum_{k=1}^{K} \lambda_{k} x_{i k} \leq \theta x_{i 0} & i=1, \ldots, N \\
\sum_{k=1}^{K} \lambda_{k} y_{j k} \geq y_{j 0} & j=1, \ldots, M \\
\lambda_{k} \geq 0 & k=1, \ldots, K
\end{array}
$$

The efficiency $\theta$ of hotel $\left(x_{0}, y_{0}\right)$ represents the minimal radial reduction of inputs that is required to reach the efficiency frontier for a specified level of outputs. The vector $\lambda$ measures the weights of peers in producing the projection of hotel $\left(x_{0}, y_{0}\right)$ on the efficiency frontier. Constraints (2) and (3) state that reference points are linear combinations of the input and output values of efficient peers for hotel $\left(x_{0}, y_{0}\right)$. (CCR) represents an LP model with $N+M$ constraints (not counting the nonnegativity constraints) and must be solved $K$ times, once for each hotel.

BCC model can be obtained from (CCR) by adding the convexity constraint that guarantees that only weighted averages of efficient hotels enter the reference set, i.e. $\sum_{k=1}^{K} \lambda_{k}=1$. CCR and BCC models are both formulated with the implicit assumption that the assessed hotels operate within homogeneous environments, which presupposes that only variables representing proper inputs are integral part of the production technology.

\section{Scale efficiency:}

Let $\theta_{C C R}^{*}$ and $\theta_{B C C}^{*}$ denote the efficiency scores of hotel $\left(x_{0}, y_{0}\right)$ calculated using CCR and BCC models, respectively. $\theta_{C C R}^{*}$ refers to the aggregate efficiency which entails two ratios: the pure technical efficiency, $\theta_{B C C}^{*}$, and the scale efficiency, SE. The score $\theta_{B C C}^{*}$ measures the managerial performance of the hotel to organize the inputs in the service process and, as a result, it identifies inefficiencies due to managerial underperformance (Manasakis et al., 2013).

The scale efficiency $S E$ assesses the managerial ability to set the optimal resource size, that is, the best production scale needed to achieve the output levels. A hotel is scale efficient when its scale efficiency is equal to one, suggesting that the hotel is operating at the most productive scale size, and any alteration of its size will lead to inefficiency. Scale inefficiency occurs for values of SE less than one, due to either increasing or decreasing returns to scale. Following Banker et al. (2004), if $\lambda^{*}$ is an optimal solution of CCR model and $\sum_{k=1}^{K} \lambda_{k}^{*}>1$, we can say that the hotel exhibits decreasing returns to scale (DRS), implying that it is operating at a scale greater than the most productive scale size of the inputs. Conversely, $\sum_{k=1}^{K} \lambda_{k}^{*}<1$ suggests that the hotel is operating in the increasing 
returns to scale (IRS) region, at a scale smaller than the most productive scale. The productivity of such hotels can be increased by transferring resources from hotels operating at DRS to those operating at IRS (Boussofiane et al., 1992).

\section{Conceptual model:}

The adequate choice of inputs and outputs for a DEA based benchmarking problem lies often on the dicta "less is better" and "more is better", respectively (Cook et al., 2014). Thus, with respect to the specific context of our study, we identified 4 outputs and 4 inputs, as shown in Figure 2.

The output variables are Annual revenue (Chiang et al., 2004; Barros and Mascarenhas, 2005; Neves and Lourenco, 2009; Pulina et al., 2010), Number of guests (Barros, 2005b), Number of nights (Barros, 2005b; Barros and Mascarenhas, 2005; Sigala et al., 2005) and Occupancy rate (Chiu et al., 2012; Ting and Huang, 2012; Yang and Lu, 2006). Annual revenue includes incomes from the rental of the hotel rooms, food and beverages served to customers, phone call bills, as well as laundry services. Number of guests counts hotel's guests, no matters the duration of their stay. Number of nights provides a cumulative value of full nights spent in the hotel. Occupancy rate refers to the proportion of hotel capacity effectively used over a specific time period (e.g. one year), i.e. number of rooms rented out over the total of rooms available. Occupancy rate has been used freshly and it is managerially useful (Perrigot et al., 2009). The input variables are Number of beds (Manasakis et al., 2013), Number of rooms (Anderson et al., 2000; Assaf et al., 2010; Barros, 2005b; Chen et al., 2010), Number of employees (Chiang et al., 2004; Barros and Mascarenhas, 2005; Hwang and Chang, 2003; Sun and Lu, 2005; Chiang, 2006; Yang and Lu, 2006; Yu and Lee, 2009), and Salary of employees (Assaf and Agbola, 2011; Morey and Dittman, 1995; Reynolds, 2003).

In order to achieve clear efficiency discrimination, Cooper et al. (2002) suggest that the minimum number $\Psi$ of DMUs must satisfy $\Psi \geq \max [M N, 3(M+N)]$. As regards our study, $N=4$ and $M=4$, implying that we need a sample of at least $\Psi=24$ hotels.

\section{Data collection:}

To collect relevant data for our study, questionnaires were distributed to all the hotels that are registered with the Ministry of Tourism in 2009. Of 107 hotels, 60 have responded and two have been discarded for missing information. The 58 hotels are spread over the seven regions of Oman (Muscat, Dhofar, Al-Buraymi, A'Dakhiliyah, A'Sharqiyah, Al-Batinah, and Musandam). Hence, we consider $K=58$ hotels, a number that is comfortably larger than $\Psi=24$. A statistical summary of the corresponding inputs and outputs is given in Table 1.

Evaluating efficiency :

To solve both CCR and BCC models for each hotel, we use IBM-ILOG CPLEX version 12.4. We compute the optimal efficiency scores $\theta^{*}$ for each hotel, besides the corresponding optimal solutions $\lambda^{*}$ and the slack values (Table 2).

Out of 58 hotels, 13 are technically efficient under CRS and more than double (27 hotels) under VRS. At an individual stakeholder's level, the aggregate efficiency measure $\theta_{C C R}^{*}$ suggests that the hotel has the flexibility to reduce specific inputs by $100\left(1-\theta_{C C R}^{*}\right) \%$ and still produce the same level of outputs. On average, the input reduction nears $30 \%$ for an average aggregate efficiency of $70 \%$. Furthermore, the average technical efficiency is 0.83 , implying that the majority of hotels are efficient in managing their resources.

Over the seven regions involved in the study, almost all the efficient hotels are located in Muscat. Such a high concentration is primarily justified, knowing that Muscat is the capital and hosts most of the country's touristic sites, besides more than half the number of hotels.

Identifying performance drivers:

Commonly, the efficiency evaluation is carried out with endogenous inputs without considering contextual factors. In the hotel industry, hotel size (Assaf et al., 2010), location (Barros, 2005a; Bernini and Guizzardi, 2010; Tundis et al., 2012), and type of ownership (Barros, 2004; Barros and Dieke, 2008; Yu and Lee, 2009) are the most popular factors which are found to be strong determinants of hotel efficiency in many case studies (Assaf et al., 2010). Other variables could also be pertinent, like star rating (Assaf and Cvelbar, 2010), used essentially to reflect quality of service, even though it is far from being a wholly satisfactory proxy for such an operational factor (Oliveira et al., 2013). 
Variables selection:

Based on previous studies, we consider four contextual variables: Type of ownership, Hotel size, Star rating and Attractions. The variable Attractions is introduced to investigate the influence of hotel's location on its efficiency. Bernini abd Guizzardi (2010) suggest that location is positively correlated with technical efficiency, especially for sun and beach destinations, as well as cities with renowned cultural importance. Thus, resources that may contribute to the attractiveness of a hotel's location need to be conserved (Gomezelj and Mihalič, 2008). The latter being nominal, it cannot be used in a regression model without a prior quantification. For that reason, the number of attractions is used as a quantitative substitute.

Based on the classification of the Ministry of tourism, there are three categories of attractions: Nature, Culture, and Activities. The items that fall under each category are as follows:

-Nature: Reserves, valleys, strait of Hormuz, mountains, caves, deserts, beaches, islands, water springs, lagoons, rocks park, canyon, Muscat geo-site.

-Culture: Aflaj system, traditional villages, souqs, world heritage, museums, forts, castles, archeological and religious sites, crafts, frankincense, cities.

-Activities: Scuba diving, boating, climbing, Via Ferrata, trekking, camping, caving, golf, kite-surfing, kiteboarding, shopping, watching (whales, birds, turtles, dolphins), racing (camels, horses), off-road, Muscat geo-heritage.

In order to gauge the individual effect of each category and draw more focused decisions, we consider them as separate variables.

Accordingly, the variable location is represented with three variables, whose values are calculated as follows. First, we identify all potential attraction sites and activities related to each destination. Next, we cluster these items based on the above classification scheme. Finally, we count the number of items for each category. Each number translates the weight of each location with respect to each attraction category. The values obtained are presented in Table 3 .

For instance, the value of variable Nature is 16 for Muscat, that is, there are potentially 16 touristic sites in Muscat corresponding to, at least, one of the items listed under category Nature. Similar reasoning applies to the other variables. Muscat is, apparently, the most attractive with respect to cultural sites, while Dhofar is leading with its natural sites. The majority of regions offer some sort of activities, except Al-Batinah.

Regarding the other contextual variables, Type of ownership is a dichotomous variable taking a value 1 if the hotel is part of a chain of hotels, a value 0 otherwise. For hotel size, we use values 0,1 or 2 depending on whether the hotel is small, medium or large, respectively, that is, the number of rooms is less than 100 , between 100 and 300 , or more than 300 . Star rating refers to the number of stars assigned to a hotel for the previous year's exercise, a number varying between 1 and 5. Ray and Phillips (2005) and Assaf and Agbola (2011) suggest that the number of stars and efficiency are positively correlated, that is, the more stars, the better the performance.

More than $67 \%$ of hotels are independent from a chain, with a close proportion of small size hotels. Such figures reflect the fact that the lodging industry in Oman is still a growing sector. The same can be read from the star ratings, with 15 hotels registered as one star and 8 only as five star hotels. The summary statistics for the contextual variables are given in Table 4.

In order to assess the cross-sectional association of these factors with the DEA efficiency scores, the second stage analysis (Fried et al., 2002) is conducted through a Tobit analysis. To enable an analysis under the operating scale of the hotels, we use the pure technical efficiency $\theta_{B C C}^{*}$ instead of $\theta_{C C R}^{*}$.

\section{Tobit regression analysis:}

Given that technical efficiency scores $\theta=\theta_{B C C}^{*}$ take continuous values in the interval $[0,1]$, Tobit regression model (Tobin, 1958) is primarily more suitable than Ordinary Least Square (OLS), the latter's estimators being biased downward for this data configuration (see, e.g., Greene, 1997).

Let $z_{1}, z_{2}, z_{3}, z_{4}, z_{5}$, and $z_{6}$ denote the contextual variables type of ownership, hotel size, star rating, nature, culture, and activities, respectively. Using the classification of Amemiya (1985), type I Tobit model (Tobin, 1958) is defined as follows:

$$
\begin{gathered}
\theta_{k}^{L}=\beta_{0}+\sum_{p=1}^{6} \beta_{p} z_{k p}+\varepsilon_{k} \quad k=1, \ldots, K \\
\theta_{k}= \begin{cases}\theta_{k}^{L} & \text { if } \theta_{k}^{L}<1 \\
1 & \text { if } \theta_{k}^{L}=1\end{cases}
\end{gathered}
$$


where $\theta$ is the dependent variable, observed for values less than 1 and censored for values of $1 . \theta^{L}$ is the latent dependent variable; $\beta$ is the vector of the model's coefficients; and $\varepsilon$ is the error term. The values of the $\varepsilon_{k}^{\prime}$ 's are assumed independent and normally distributed; i.e., $\varepsilon_{k} \sim N(0, \sigma)$. Each estimated coefficient $\hat{\beta}_{p}$ is interpreted as the marginal effect of a change in $z_{p}$ on the latent variable $\theta^{L}$. We used $\mathrm{R}$ software for statistical analysis to estimate the parameters of model (5). The regression results are displayed in Table 5.

The squared correlation between the predicted and observed values of $\theta_{B C C}^{*}$ is $R^{2}=0.03186$, indicating that predicted values share only $3.18 \%$ of their variance with $\theta_{B C C}^{*}$. Hence, there is globally no significant relationship between the hotel efficiency and the selected set of contextual variables. Moreover, all the $p$-values being above $10 \%$, failure to achieve statistical significance is by far the dominant result for every one of the contextual variables.

Theoretically, the failure of Tobit model to provide valid inference can be imputed to the fact that conventional inference methods use DEA estimates of efficiency, which are correlated by construction, instead of true efficiency (Simar \& Wilson, 2011). However, the intuitive explanation for such a failure is the "double role" played by some output variables, specifically Number of guests, Number of nights and Occupancy rate. In spite of being perceived as outputs with respect to the dictum "more is better" of a DEA based benchmarking problem (Cook et al., 2014), these variables can also be treated as exogenous variables in a production system whose objective is maximizing profit. Effectively, the output Annual revenue itself depends on these variables, and such a property alone can affect some results if handled outside the DEA framework. To assess this hypothesis, we developed a production model integrating all variables within a unified framework that (1) preserves the role of the latter output variables in generating the efficiency estimates and enhances their contribution as potential exogenous variables, (2) circumvents the autocorrelation of DEA efficiency estimates, and (3) allows for the results of the DEA stage to be further assessed..
Integrated stochastic model

Banker \& Natarajan (2008) remark that "we cannot theoretically justify the use of a Tobit regression in the second stage in terms of an underlying datagenerating process". As an alternative, the authors propose a statistical model in which the second-stage regression equation is log-linear and writes the efficiency score $\theta$ in terms of the contextual variables $z$ as:

$$
\ln \theta=\beta_{0}-\sum_{p=1}^{6} \beta_{p} z_{p}+\omega
$$

where $\beta_{p}, p=1, \ldots, 6$ are the model's parameters, and $\omega$ is the error term which follows a two-sided distribution. Assuming normality, $\omega \sim N\left(0, \sigma_{\omega}^{2}\right)$. The application of the proposed approach to our case study gives the results shown in Table 6 .

The overall significance level is only $90.998 \%$ and the adjusted $R^{2}=-7.414 \%$, indicating that the log-linear model fails to show any relationship between the hotel efficiency and the contextual variables.

Let $x_{1}, x_{2}, x_{3}$ and $x_{4}$ represent the input variables Number of beds, Number of rooms, Number of employees, and Salary of employees, respectively. We also denote by $y_{1} x_{5}, x_{6}$ and $x_{7}$ the output variables Annual revenue, Number of guests, Number of nights and Occupancy rate, respectively. Assuming that the entire industry is described by a Cobb-Douglas production function, $y=\delta_{0} \prod_{i=1}^{7} x_{i}^{\delta i} e^{\gamma}$

where $\delta$ is the vector of unknown parameters, and $\gamma$ is the stochastic disturbance term (Gujarati, 2003). Under normality assumption, $\gamma \sim N\left(0, \sigma_{\gamma}^{2}\right)$.

From (6), we can write: $\exp \left(\ln \theta-\beta_{0}+\sum_{p=1}^{6} \beta_{p} z_{p}-\omega\right)=1$

Multiplying the left-hand side of (8) by the right-hand side of (7), we have, after manipulation:

$$
y / \theta=\delta_{0} \exp \left(-\beta_{0}\right) \prod_{i=1}^{7} x_{i}^{\delta i} \exp \left(\sum_{p=1}^{6} \beta_{p} z_{p}+\gamma-\omega\right)
$$

Setting $\quad y^{*}=y / \theta, \quad \beta_{0}^{*}=\delta_{0} \exp \left(-\beta_{0}\right) \quad$ and $\varepsilon^{*}=\gamma-\omega$, and log-transforming,

$$
\ln y^{*}=\ln \beta_{0}^{*}+\sum_{i=1}^{7} \delta_{i} \ln x_{i}+\sum_{p=1}^{6} \beta_{p} z_{p}+\varepsilon^{*}
$$


Equation (9) represents a production function that incorporates all variables into a linear model, with $\ln x_{i}$ and $z_{p}$ as independent variables and $\ln y^{*}$ as a dependent variable.

With $\varepsilon^{*} \sim N\left(0, \sigma_{\gamma}^{2}+\sigma_{\omega}^{2}\right)$, ordinary least square (OLS) can be used to estimate the model's parameters and OLS estimators are equivalent to the maximum likelihood estimators, and therefore are asymptotically efficient in the class of all regular estimators. Meanwhile, note that the variable $z_{2}$ (hotel size) is dropped from the model since it is, by definition, correlated with the variable $x_{2}$ (number of rooms). The outputs of the regression analysis are given in Table7.

The $p$-value of the F-test is nearly zero $\left(1.43 \times 10^{-23}\right)$. Hence, the multiple regression relationship is significant. The value of the adjusted coefficient of determination reveals that $93.06 \%$ of the variability in $\ln y^{*}$ is explained by $\ln x_{i}{ }^{\prime} s$ and $z_{p}{ }^{\prime}$ s, meaning that the estimated multiple regression equation fits the data very well. Furthermore, RTS $=1.796$ indicates that the entire industry displays increasing returns to scale. With respect to individual significance levels, the results show that variables Type of ownership, Nature and Activities are statistically insignificant, with $p$ values larger than $10 \%$. In addition, the negative coefficients of variables Nature and Activities suggest a negative contribution to hotel efficiency. This may also advocate that these factors are not important drivers for choosing a specific hotel location.

Number of rooms (viz. hotel size), Star rating and Culture are found to have the most significant effect on efficiency, with all p-values smaller than $5 \%$. This confirms, to some extent, the outcome of the DEA analysis. The positive impact of Star rating on efficiency conforms to the findings of Ray and Phillips (2005) as well as Assaf and Agbola (2011).

Variable Culture seems affecting efficiency positively, although with a lower intensity $\left(\hat{\beta}_{5}=0.07194\right)$. This can inform policy makers on the necessity to preserve and promote cultural heritage as an important key factor of attraction. In an attempt to depict customers' profile, this may also reveal that most of the hotels' guests are educated tourists, looking for knowledge and discovery. In addition, Star-rating is found to be an important determinant of efficiency. In practice, this result remains consistent with the natural parity quality-demand.
Conclusions, implications and future research

As the first analysis of the performance of the hospitality industry in Oman, the present study involved a sample of 58 hotels from different regions of the country. The estimation of technical efficiency revealed an average score of 0.83 under current operating scales, with about $45 \%$ of the hotels identified as efficient. Near $66 \%$ of the efficient hotels are located in Muscat, due probably to the high concentration of hotels (62\% of the country's lodging capacity) besides the attractiveness of the city as the capital of the country and the key business place. Such facts suggest more investment policies decentralized towards boosting the hospitality industry other regions rather than the capital and its peripherals. ,

Potential sources of inefficiency are initially investigated through an analysis of scale economies, which indicated that the optimal size of a hotel should be, on average, 73 rooms, with $\$ 3.13 \mathrm{~m} /$ year expected revenue and an occupancy rate of $68.07 \%$. Moreover, $76.2 \%$ of the total number of hotels exceeds the scale efficiency level of 0.90 for an average of 0.85 . With a sample representing $54.20 \%$ of the population of hotels (58 out of 107), these are enough indicators that most hotels are operating near the optimal size, endorsing, as a matter of fact, previous investment choices and discarding hotel size as a key factor of inefficiency. Based on the slack analysis, it appeared important to perform a performance evaluation using disaggregated input variables so that to discern precisely the inefficiency sources.

At an advanced stage, the effect of environmental factors on efficiency has been explored using Tobit and log-linear regression models with, for the first time, destination attractiveness quantified by more than one variable. Failure of both models to achieve statistical significance prompted the idea of developing a new production model that incorporates both controllable and uncontrollable variables. The new model revealed that Type of ownership (independent or chain dependent), Nature and Activities have no impact on the choice of a hotel, whilst Hotel size, Star rating and Culture appear as the most influential factors. The variable Culture is particularly interesting as a factor translating that hotels' visitors belong to a specific category of customers. As a result, marketing strategies ought to be adjusted so that the profiles of targeted tourists fit 
within the scope of other attractions, like nature and activities.

Regarding methodology, this study enhanced the importance of using different analytical methods to build credible inferences. Future research could consider incorporating all of the variables into the same model using extended DEA models (e.g. Banker and Morey, 1986a,b). In addition, the effect of the variable selection on decision outcomes may suggest enriching future studies with more input and output variables, together with a horizon extension covering more than one year, so that to capture the efficiency's dynamics.

\section{References:}

Anderson, R.I., Fish, M., Xia, Y. and Michello, F. 1999. Measuring efficiency in the hotel industry: a stochastic frontier approach. International Journal of Hospitality Management 181.

Anderson, R.I., Fok, R. and Scott, J. 2000. Hotel industry efficiency: An advanced linear programming examination. American Business Review 181.

Amemiya, T. 1985. Advanced Econometrics. Oxford: Basil Blackwell.

Ashrafi, A., Seow, H-.V., Lee, L.S. and Lee, C.G. 2013. The efficiency of the hotel industry in Singapore. Tourism Management 37.

Assaf, A.G. 2012. Benchmarking the Asia Pacific tourism industry: A Bayesian combination of DEA and stochastic frontier. Tourism Management 33.

Assaf, A.G. and Agbola, F. 2011. Modelling the performance of Australian hotels: a DEA double bootstrap approach. Tourism Economics 171.

Assaf, A.G. and Barros, C. 2011. Performance analysis of the Gulf hotel industry: A Malmquist index with bias correction. International Journal of Hospitality Management 304.

Assaf, A.G., Barros, C.P. and Josiassen, A. 2010. Hotel efficiency: A bootstrapped metafrontier approach. International Journal of Hospitality Management 293.
Assaf A.G. and Cvelbar L.K. 2010. The performance of the Slovenian hotel industry: evaluation postprivatisation. International Journal of Tourism Research 125.

Avkiran, N.K. 2002. Monitoring hotel performance. Journal of Asia Pacific Business 41.

Banker, R.D., Charnes, A. and Cooper, W.W. 1984. Some models for estimating technical and scale inefficiencies in data envelopment analysis. Management Science 309.

Banker, R.D., Cooper, W.W., Seiford, L.M., Thrall, R.M. and Zhu, J. 2004. Returns to scale in different DEA models. European Journal of Operational Research 1542.

Banker, R.D. and Morey, R.C. 1986a. Efficiency analysis for exogenously fixed inputs and outputs. Operations Research 344.

Banker, R.D. and Morey, R.C. 1986b. The use of categorical variables in data envelopment analysis. Management Science 3212.

Banker, R.D. and Natarajan, R. 2008. Evaluating contextual variables affecting productivity using data envelopment analysis. Operations Research 56.

Barros, C. P. 2004. A stochastic cost frontier in the Portuguese hotel industry. Tourism Economics 102.

Barros, C.P. 2005a. Evaluating the efficiency of a small hotel chain with a Malmquist productivity index. The International Journal of Tourism Research 73.

Barros, C.P. 2005b. Measuring efficiency in the hotel sector. Annals of Tourism Research 322.

Barros, C.P. 2006. Analyzing the rate of technical change in the Portuguese hotel industry. Tourism Economics 123.

Barros, C.P. and Alves, F.P. 2004. Productivity in the tourism industry. International Advances in Economics Resources 103. 
Barros, C.P., Botti, L., Peypoch, N. and Solonandrasana, B. 2011. Managerial efficiency and hospitality industry: the Portuguese case. Applied Economics 4322.

Barros, C.P. and Dieke, P.U.C. 2008. Technical efficiency of African hotels. International Journal of Hospitality Management 273.

Barros, C.P. and Mascarenhas, M.J. 2005. Technical and allocative efficiency in a chain of small hotels. International Journal of Hospitality Management 243.

Barros, C.P., Peypoch, N. and Solonandrasana, B. 2009. Efficiency and productivity growth in hotel industry. International Journal of Tourism Research 114.

Barros, C.A. and Santos, C.A. 2006. The measurement of efficiency in Portuguese hotels using data envelopment analysis. Journal of Hospitality and Tourism Research 303.

Bell, R.A. and Morey, R.C. 1994. The search for appropriate benchmarking partners- A macro approach and application to corporate travel management. Omega 25.

Bell, R.A. and Morey, R.C. 1995. Increasing the efficiency of corporate travel management through macro benchmarking. Journal of Travel Research 333.

Bernini, C. and Guizzardi, A. 2010. Internal and locational factors affecting hotel industry efficiency: evidence from Italian business corporations. Tourism Economics 164.

Botti, L., Briec, W. and Cliquet, G. 2009. Plural forms versus franchise and company-owned systems: A DEA approach of hotel chain performance. Omega 373

Boussofiane, A., Dyson, R.G. and Thanassoulis, E. 1992. Applied data envelopment analysis. European Journal of Operation Research 521.

Brown, J.R. and Ragsdale, C.T. 2002. The competitive market efficiency of hotel brands: An application of data envelopment analysis. Journal of Hospitality and Tourism Research 264.
Carvalho, P. and Marques, R. 2011. On evaluating efficiency of groups of observations. Working Paper, Lisbon: IST.

Charnes, A., Cooper, W.W. and Rhodes, E. 1978. Measuring the efficiency of decision making units. European Journal of Operational Research 26.

Chen, C.F. 2007. Applying the stochastic frontier approach to measure hotel managerial efficiency in Taiwan. Tourism Management 283.

Chen, T.H. 2009. Performance measurement of an enterprise and business units with an application to a Taiwanese hotel chain. International Journal of Hospitality Management 283.

Chen, T.H. 2011. Performance Measurement in a small Taiwanese hotel chain. Cornell Hospitality Quarterly 523.

Chen, C.T., Hu, J.L. and Lin, S.L. 2014. Regional environmental quality and cost efficiency of international tourist hotels in Taiwan. Energy and Environment Research 43.

Chen, C.T., Hu, J.L. and Liao, J.J. 2010. Tourists' nationalities and the cost efficiency of international tourist hotels in Taiwan. African Journal of Business Management 416.

Chiang, W. 2006. A hotel performance evaluation of Taipei international tourist hotels using data envelopment analysis. Asia Pacific Journal of Tourism Research 111.

Chiang, W., Tsai, M. and Wang, L.S. 2004. A DEA evaluation of Taipei hotels. Annals of Tourism Research 313.

Chin, J.B., Wu, M.C. and Hsieh, L.F. 2013. Strategic planning of optimal resource allocation in response to global financial crisis - A study of international tourist hotels. Applied Economics 4523.

Chiu, Y.H. and Huang, C.W. 2011. Evaluating the optimal occupancy rate, operational efficiency and profitability efficiency of Taiwan's international tourist hotels. The Service Industries Journal 3113. 
Chiu, Y., Huang, C. and Ting, C. 2012. A non-radial measure of different systems for Taiwanese tourist hotels' efficiency assessment. Central European Journal of Operations Research 201.

Choufany, H. M. and Younes, E. 2005. Oman today's spotlight, tomorrow's destination. HVS International London, available at:

http://www.hvs.com/Content/1687.pdf

Coelli, T., Rao, D.S.P. and Battese, G.E. 1998. An introduction to efficiency and productivity analysis, Kluwer Academic Publishers, Massachusetts, USA.

Coelli, T., Rao, D.S.P. O'Donnell, C.J. and Battese, G.E. 2005. An Introduction to efficiency and productivity analysis, Springer, New York.

Cook, W.D., Tone, K. and Zhu, J. 2014. Data envelopment analysis: Prior to choosing a model. Omega 441.

Cooper, W.W., Seiford, L.M. and Tone, H. 2002. Data envelopment analysis: A comprehensive text with models, applications, references and DEA-Solver software, Kluwer Academic Publisher, N.Y.

Donaghy, K., McMahon, U. and McDowell, D. 1995. Yield Management: An overview. International Journal of Hospitality Management 142.

Fernández, M.A. and Becerra, R. 2013. An Analysis of Spanish Hotel Efficiency. Cornell Hospitality Quarterly, doi: $10.1177 / 1938965513509877$

Fried, H.O., Lovell, C.A.K., Schmidt, S.S. and Yaisawarng, S. 2002. Accounting for environmental effects and statistical noise in data envelopment analysis. Journal of Productivity Analysis 171-2.

Gomezelj, O. and Mihalič, T. 2008. Destination competitiveness - applying different models, the case of Slovenia. Tourism Management 292.

Greene, W. 1997. Econometric analysis, Macmillan, New York.

Greene, W. 2008. The econometric approach to efficiency analysis. in Fried, H.O., Lovell, C.A.K. and
Schmidt, S.S. Eds, The measurement of productive efficiency and productivity growth, Oxford University Press.

Gujarati, D.N. 2003. Basic Econometrics, McGrawHill Higher Education.

Hadad, Y., Friedman, L. and Israeli, A.A. 2005. Evaluating hotel advertisements efficiency using data envelopment analysis. Journal of Business Economics and Management 63.

Hathroubi, S., Peypoch, N. and Robinot, E. 2014. Technical efficiency and environmental management: The Tunisian case. Journal of Hospitality and Tourism Management 211.

Hoff, A. 2007. Second stage DEA: Comparison of approaches for modelling the DEA score. European Journal of Operational Research 181.

Hokey, M., Hyesung, M. and Seong-Jong, J. 2008. A data envelopment analysis-based balanced scorecard for measuring the comparative efficiency of Korean luxury hotels. International Journal of Quality and Reliability Management 254.

Honma, S. and Hu, J.L. 2012. Analyzing Japanese hotel efficiency. Tourism and Hospitality Research 123.

Hruschka, H. 1986. Ansätze der efflzienzmessung von betrieben, Journal für Betriebswirtschaft : management review quarterly 362 .

Hsieh, L.F., Wang, L.H., Huang, Y.C. and Chen, A. 2010. An efficiency and effectiveness model for international tourist hotels in Taiwan. The Service Industries Journal 3013.

Hu, B.A. and Cai, L.A. 2004. Hotel labor productivity assessment: A data envelopment analysis. Journal of Travel and Tourism Marketing 162-3.

Hu, J.L., Chiu, C.N., Shieh, H.S. and Huang, C.H. 2010. A stochastic cost efficiency analysis of international tourist hotels in Taiwan. International Journal of Hospitality Management 291. 
Hu, J.L., Shieh, H.S., Huang, C.H. and Chiu, C.N. 2009. Cost efficiency of international tourist hotels in Taiwan: A data envelopment analysis application. Asia Pacific Journal of Tourism Research 144.

Hu, J.L., Yeh, F.Y. and Tsai, Y.C.2014. Regional traffic and medical services and cost efficiency of international tourist hotels in Taiwan. International Business Research 710.

Huang, C., Ho, F.N. and Chiu, Y. 2014. Measurement of tourist hotels' productive efficiency, occupancy and catering service effectiveness using a modified twostage DEA model in Taiwan. Omega 48.

Huang, Y., Mesak, H.I., Hsu, M.K. and Qu, H. 2012. Dynamic efficiency assessment of the Chinese hotel industry. Journal of Business Research 651, pp. 59-67. Hwang, S.N. and Chang, T.Y. 2003. Using data envelopment analysis to measure hotel managerial efficiency change in Taiwan. Tourism Management 244.

Ithraa. 2016. Oman's Vision 2020 Objectives. https://ithraa.om/Economic-Overview

Jeong, S.O., Park, B.U. and Simar, L. 2010. Nonparametric conditional efficiency measures: asymptotic properties. Annals of Operational Research 173.

Johns, N., Howcroft, B. and Drake, L. 1997. The use of data envelopment analysis to monitor hotel productivity. Progress in Hospitality and Tourism 32.

Keh, H.T., Chu, S. and Xu, J. 2006. Efficiency, effectiveness and productivity of marketing in services. European Journal of Operational Research 1701

Kimes, S.E. 1989. The basics of yield management. Cornell Hotel and Restaurant Administration Quarterly 303.

Lin, C.H., Chiu, Y.H. and Huang, C.W. 2012. Assessment of technology gaps of tourist hotels in productive and service processes. The Service Industries Journal 3214.

Liu, J.S., Lu, L.Y.Y., Lu, W.M. and Lin, B.J.Y. 2013. A Survey of DEA applications. Omega 415.
McDonald, J. 2009. Using least squares and tobit in second stage DEA efficiency analyses. European Journal of Operational Research 197.

Manasakis, C., Apostolakis, A. and Datseris, G. 2013. Using data envelopment analysis to measure hotel efficiency in Crete. International Journal of Contemporary Hospitality Management 254.

Min, H., Min, H., Joo, S.J. and Kim, J. 2009. Evaluating the financial performances of Korean luxury hotels using data envelopment analysis. The Service Industries Journal 296.

Min, H., Min, H. and Joo, S.J. 2009. A data envelopment analysis on assessing the competitiveness of Korean hotels. The Service Industries Journal 293.

Morey, R. and Dittman, D. 1995. Evaluating a hotel GM's performance: A case study in benchmarking. Cornell Hotel and Restaurant Administration Quarterly 365.

Morey, R. and Dittman, D. 2003. Update and Extension to "Evaluating a hotel GM's performance. Cornell Hotel and Restaurant Administration Quarterly 445-6.

Neves, J., Lourenco, S. 2009. Using data envelopment analysis to select strategies that improve the performance of hotel companies. International Journal of Contemporary Hospitality Management 216,.

Oliveira, R., Pedro, M.I. and Marques, R.C. 2013. Efficiency and its determinants in Portuguese hotels in the Algarve. Tourism Management 36.

Önüt, S. and Soner, S. 2006. Energy efficiency assessment for the Antalya Region hotels in Turkey. Energy and Buildings 388.

Perrigot, R., Cliquet, G. and Piot-Lepetit, I. 2009. Plural form chain and efficiency: Insights from the French hotel chains and the DEA methodology. European Management Journal 274.

Pulina, M., Detotto, C. and Paba, A. 2010. An investigation into the relationship between size and efficiency of the Italian hospitality sector: a window 
DEA approach. European Journal of Operational Research 2043.

QNB 2013. Oman Economic Insight 2013, Qatar National Bank available at:

http://www.qnb.com/cs/Satellite?blobcol=urldata\&bl obheader=application\%2Fpdf\&blobkey=id\&blobtable= MungoBlobs\&blobwhere $=1355489088869 \&$ ssbinary $=t$ rue

Rahmati, E. and Jalil, S.H.A. 2014. Efficiency and Effectiveness of Marketing of the Hotels in Kuala Lumpur. International Journal of Economics and Management 81.

Ramalho, E.A., Ramalho, J.J.S. and Henriques, P.D. 2010. Fractional regression models for second stage DEA efficiency analyses. Journal of Productivity Analysis 34.

Ray, P. and Phillips, P. 2005. Performance comparisons of hotels in China. International Journal of Hospitality Management 241.

Reynolds, D. 2003. Hospitality-productivity assessment using data envelopment analysis. Cornell Hotel and Restaurant Administration Quarterly 442.

Sampaio de Sousa, M. and Stosic, B. 2005. Technical efficiency of the Brazilian municipalities correcting nonparametric frontier measurement of outliers. Journal of Productivity Analysis 242.

Sanjeev, G. 2007. Measuring efficiency of the hotel and restaurant sector: the case of India. International Journal of Contemporary Hospitality Management 195.

Shang, J., Hung, W., Lo, C., andWang, F. 2008. Ecommerce and hotel performance: Three-stage DEA analysis. The Service Industries Journal 284.

Shang, J., Wang, F. and Hung, W. 2010. A stochastic DEA study of hotel efficiency. Applied Economics 4219.

Sharma, A. and Sneed, J. 2008. Performance analysis of small hotels in Tanzania. Journal of Services Research, Special Issue.
Shirouyehzad, H., Hosseinzadeh Lotfi, F., Shahin, A., Aryanezhad, M.B. and Dabestani, R. 2012. A DEA approach for comparative analysis of service quality dimensions with a case study in hotel industry. International Journal of Services and Operations Management 123.

Shyu, J. and Hung, S.C. 2012. The true managerial efficiency of international tourist hotels in Taiwan: Three-stage data envelopment analysis. The Service Industries Journal 3212.

Sigala, M. 2004. Using Data Envelopment Analysis for Measuring and Benchmarking Productivity in the Hotel Sector. Journal of Travel and Tourism Marketing 162-3.

Sigala, M., Airey, D., Jones, P. and Lockwood, A. 2004. ICT paradox lost? A stepwise DEA methodology to evaluate technology investments in tourism settings. Journal of Travel Research 432.

Sigala, M., Jones, P., Lockwood, A. and Airey, D. 2005. Productivity in hotels: A stepwise data envelopment analysis of hotels' rooms division processes. The Service Industries Journal 251.

Simar, L. and Wilson, P.W. 2007. Estimation and inference in two-stage, semi-parametric models of production processes. Journal of Econometrics 1361.

Simar, L. and Wilson, P.W. 2011. Two-stage DEA: caveat emptor. Journal of Productivity Analysis 36.

Subramoniam, S., Al-Essai, S.A.N., Al-Marshadi, A.A.M. and Al-Kindi, A.M.A. 2010. SWOT analysis on Oman tourism: a case study. Journal of Economics Development, Management, IT, Finance and Marketing 22.

Sun, S. and Lu, W.M. 2005. Evaluating the performance of the Taiwanese hotel industry using a weight slacksbased measure. Asia-Pacific Journal of Operational Research 224.

Tarim, Ş., Dener, H.I. and Tarim, Ş.A. 2000. Efficiency Measurement in the hotel industry: Output Factor Constrained DEA application. Anatolia: An International Journal of Tourism and Hospitality Research 112. 
Ting, C.T. and Huang, C.W. 2012. Measuring the effectiveness of mutual learning for Taiwan's tourist hotels with the DEA approach. Cornell Hospitality Quarterly 531.

Tobin, J. 1958. Estimation of Relationships for Limited Dependent Variables. Econometrica 261.

Tsai, H. 2009. Star-rated hotel productivity in China: A provincial analysis using the DEA cross-efficiency evaluation approach. Journal of China Tourism Research 53.

Tumer, N. 2010. Measuring hotel performance using data envelopment analysis. Anatolia: An International Journal of Tourism and Hospitality Research 212.

Tundis, E., Corsino, M. and Zaninotto, E. 2012. Revealing the influence of managerial practices and entrepreneurs' characteristics on hotel efficiency. DISA Working Papers, Trento University, Italy.

Wang, F.C., Hung, W.T. and Shang, J.K. 2006. Measuring pure managerial efficiency of international tourist hotels in Taiwan. The Service Industries Journal 261.

Wassenaar, D.J. and Stafford, E.R. 1991. The lodging index: An economic indicator for the hotel/motel industry. Journal of Travel Research 301.

WEF 2013. The travel and tourism competitiveness report 2013. World Economic Forum. Available at http://www3.weforum.org/docs/WEF_TT_Competitive ness_Report_2013.pdf

Wijeysinghe, B.S. 1993. Breakeven occupancy for a hotel operation. Management Accounting 712.

Winckler, O. 2007. The Birth of Oman's Tourism Industry. Tourism - An International Interdisciplinary Journal 552.

Wöber, K.W. 2002. Benchmarking in tourism and hospitality industries: The selection of benchmarking partners, CABI Publishing, Oxford.

Wöber, K.W. 2007. Data Envelopment Analysis. Journal of Travel and Tourism Marketing 214.
WTTC 2013. Travel and tourism economic impact 2013, Oman. World Travel and Tourism Council, Available at:

http://www.wttc.org/site_media/uploads/downloads/ world2013_1.pdf

Wu, D.D., Yang, Z., Vela, S. and Liang, L. 2007. Simultaneous analysis of production and investment performance of Canadian life and health insurance companies using DEA. Computers and Operations Research 21.

Yang, C. and Lu, W.M. 2006. Performance benchmarking for Taiwan's international tourist hotels. INFOR 443.

$\mathrm{Yu}, \mathrm{M}$. and Lee, B. 2009. Efficiency and effectiveness of service business: Evidence from international tourist hotels in Taiwan. Tourism Management 304, pp. 57180.

Zhang, Q. and Ma, J. 2011. Research on business efficiency of hotel and tourism enterprises based on the influence of innovation factors. Energy Procedia 5.

Zhou, Z., Huang, Y. and Hsu, M.K. 2008. Using data envelopment analysis to evaluate efficiency: An exploratory study of the Chinese hotel industry. Journal of Quality Assurance in Hospitality and Tourism 93. 


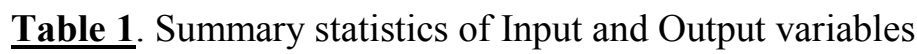

\begin{tabular}{|l|l|c|c|c|c|}
\hline Variables & Unit & Mean & SD & Min. & Max. \\
\hline Output & & & & & \\
\hline Annual revenue & \$/year & $6,911,989$ & $13,731,079$ & 3,004 & $78,795,452$ \\
\hline Number of guests & & 17,864 & 20,273 & 597 & 96,877 \\
\hline Number of nights & & 23,882 & 28,091 & 669 & 147,084 \\
\hline Occupancy rate & $\%$ & 55 & 24 & 2 & 87 \\
\hline Inputs & & & & & \\
\hline Number of beds & & 135 & 138 & 23 & 937 \\
\hline Number of rooms & & 91 & 97 & 13 & 640 \\
\hline Number of employees & & 111 & 191 & 4 & 1,193 \\
\hline Salary of employees & \$/year & $1,040,976$ & $2,197,535$ & 14,344 & $11,704,068$ \\
\hline
\end{tabular}

Table 2. Hotel specific efficiency scores using DEA

\begin{tabular}{|c|c|c|c|c|c|}
\hline Hotel & $\theta_{C C R}^{*}$ & $\theta_{B C C}^{*}$ & SE & $\sum_{k=1}^{K} \lambda_{k}^{*}$ & Status \\
\hline H1 & 0.72 & 0.76 & 0.96 & 3.70 & decr. \\
\hline $\mathrm{H} 2$ & 0.86 & 0.87 & 0.99 & 3.68 & decr. \\
\hline H3 & 1.00 & 1.00 & 1.00 & 1.00 & const. \\
\hline H4 & 1.00 & 1.00 & 1.00 & 1.00 & const. \\
\hline H5 & 0.67 & 1.00 & 0.67 & 6.36 & decr. \\
\hline H6 & 0.79 & 0.81 & 0.97 & 1.20 & decr. \\
\hline $\mathrm{H7}$ & 0.73 & 1.00 & 0.73 & 1.90 & decr. \\
\hline H8 & 0.96 & 1.00 & 0.96 & 2.34 & decr. \\
\hline H9 & 0.87 & 1.00 & 0.87 & 2.61 & decr. \\
\hline $\mathrm{H} 10$ & 0.50 & 0.51 & 0.99 & 0.92 & incr. \\
\hline H11 & 0.89 & 1.00 & 0.89 & 1.74 & decr. \\
\hline $\mathrm{H} 12$ & 0.74 & 0.93 & 0.79 & 1.55 & decr. \\
\hline H13 & 0.39 & 0.40 & 0.99 & 1.05 & decr. \\
\hline H14 & 1.00 & 1.00 & 1.00 & 1.00 & const. \\
\hline H15 & 1.00 & 1.00 & 1.00 & 1.00 & const. \\
\hline H16 & 1.00 & 1.00 & 1.00 & 1.00 & const. \\
\hline $\mathrm{H} 17$ & 0.80 & 0.80 & 0.99 & 1.01 & decr. \\
\hline H18 & 0.48 & 1.00 & 0.48 & 1.22 & decr. \\
\hline H19 & 0.46 & 0.52 & 0.89 & 1.08 & decr. \\
\hline $\mathrm{H} 2 \mathrm{O}$ & 0.50 & 0.51 & 0.99 & 0.97 & incr. \\
\hline H2 1 & 0.51 & 0.51 & 0.98 & 0.87 & incr. \\
\hline H22 & 0.41 & 0.46 & 0.89 & 0.86 & incr. \\
\hline H23 & 0.75 & 0.77 & 0.98 & 0.90 & incr. \\
\hline H24 & 0.69 & 1.00 & 0.69 & 1.35 & decr. \\
\hline H25 & 1.00 & 1.00 & 1.00 & 1.00 & const. \\
\hline H26 & 1.00 & 1.00 & 1.00 & 1.00 & const. \\
\hline $\mathrm{H} 27$ & 0.25 & 1.00 & 0.25 & 0.15 & incr. \\
\hline H28 & 1.00 & 1.00 & 1.00 & 1.00 & const. \\
\hline H29 & 0.93 & 0.95 & 0.98 & 1.13 & decr. \\
\hline $\mathrm{H} 30$ & 1.00 & 1.00 & 1.00 & 1.00 & const. \\
\hline H31 & 1.00 & 1.00 & 1.00 & 1.00 & const. \\
\hline H32 & 1.00 & 1.00 & 1.00 & 1.00 & const. \\
\hline H33 & 0.74 & 0.81 & 0.92 & 1.51 & decr. \\
\hline H34 & 0.22 & 0.23 & 0.94 & 0.75 & incr. \\
\hline H35 & 0.75 & 0.80 & 0.94 & 1.69 & decr. \\
\hline H36 & 0.11 & 0.37 & 0.30 & 0.16 & incr. \\
\hline H37 & 0.50 & 1.00 & 0.50 & 0.30 & incr. \\
\hline H38 & 0.47 & 1.00 & 0.47 & 0.17 & incr. \\
\hline H39 & 0.84 & 0.99 & 0.85 & 1.31 & decr. \\
\hline $\mathrm{H} 4 \mathrm{O}$ & 1.00 & 1.00 & 1.00 & 1.00 & const. \\
\hline H41 & 0.95 & 1.00 & 0.95 & 0.68 & incr. \\
\hline $\mathrm{H} 42$ & 0.67 & 0.76 & 0.88 & 1.14 & decr. \\
\hline H43 & 0.74 & 0.75 & 1.00 & 0.98 & incr. \\
\hline H44 & 0.62 & 0.65 & 0.95 & 0.83 & incr. \\
\hline H45 & 0.61 & 0.90 & 0.68 & 0.53 & incr. \\
\hline H46 & 0.11 & 0.63 & 0.17 & 0.10 & incr. \\
\hline H47 & 0.53 & 0.53 & 0.98 & 0.81 & incr. \\
\hline H48 & 0.32 & 0.32 & 0.99 & 1.05 & decr. \\
\hline H49 & 0.41 & 0.77 & 0.53 & 0.31 & incr. \\
\hline $\mathrm{H} 50$ & 0.50 & 0.50 & 0.99 & 0.87 & incr. \\
\hline H5 1 & 0.88 & 0.92 & 0.96 & 1.15 & decr. \\
\hline H52 & 0.92 & 1.00 & 0.92 & 1.09 & decr. \\
\hline H53 & 0.76 & 0.94 & 0.81 & 1.27 & decr. \\
\hline H54 & 0.89 & 1.00 & 0.89 & 0.77 & incr. \\
\hline H55 & 0.22 & 0.59 & 0.37 & 0.19 & incr. \\
\hline H56 & 1.00 & 1.00 & 1.00 & 1.00 & const. \\
\hline H57 & 0.17 & 1.00 & 0.17 & 0.14 & incr. \\
\hline H58 & 0.97 & 0.99 & 0.99 & 1.13 & decr. \\
\hline
\end{tabular}


Table 3. Quantification of attraction categories

\begin{tabular}{|l|c|c|c|}
\hline Region & Nature & Culture & Activities \\
\hline Muscat & 16 & 16 & 13 \\
\hline Dhofar & 19 & 8 & 13 \\
\hline Al Buraymi & 5 & 5 & 13 \\
\hline A'Dakhiliyah & 11 & 12 & 12 \\
\hline A'Sharqiyah & 2 & 6 & 3 \\
\hline Al Batinah & 1 & 3 & 0 \\
\hline Musandam & 4 & 1 & 9 \\
\hline
\end{tabular}

Table 4. Summary statistics of hotel contextual factors

\begin{tabular}{|l|l|c|c|c|c|}
\hline Variables & Unit & Mean & SD & Min. & Max. \\
\hline Type of ownership & categorical & 0.33 & 0.47 & 0 & 1 \\
\hline Hotel size & categorical & 1.33 & 0.51 & 1 & 3 \\
\hline Star rating & categorical & 2.81 & 1.41 & 1 & 5 \\
\hline Attractions: & & & & & \\
\hline - Nature & & 12.36 & 6.37 & 1.00 & 19.00 \\
\hline - Culture & & 11.55 & 5.33 & 1.00 & 16.00 \\
\hline - Activities & & 10.53 & 4.81 & 0.00 & 13.00 \\
\hline
\end{tabular}

Table 5. Outputs of the Tobit regression analysis

\begin{tabular}{|c|c|c|c|}
\hline Coefficients & Value & t value & p-value \\
\hline$\beta_{0}$ & 0.82295 & 7.60844 & 0.00000 \\
\hline$\beta_{a}$ & -1.53399 & -16.52044 & 0.00000 \\
\hline$\beta_{1}$ & 0.03740 & 0.45247 & 0.65184 \\
\hline$\beta_{2}$ & 0.02129 & 0.24326 & 0.80827 \\
\hline$\beta_{3}$ & -0.02448 & -0.73774 & 0.46227 \\
\hline$\beta_{4}$ & -0.00963 & -0.93575 & 0.35149 \\
\hline$\beta_{5}$ & 0.00309 & 0.34920 & 0.72762 \\
\hline$\beta_{6}$ & 0.01141 & 0.89478 & 0.37289 \\
\hline
\end{tabular}

Table 6. Outputs of the log-linear regression analysis

\begin{tabular}{|c|c|c|c|}
\hline Coefficients & Value & t value & p-value \\
\hline$\beta_{0}$ & -0.25896 & -1.45439 & 0.15197 \\
\hline$\beta_{a}$ & 0.02714 & 0.19950 & 0.84267 \\
\hline$\beta_{1}$ & 0.01808 & 0.12552 & 0.90061 \\
\hline$\beta_{2}$ & -0.02848 & -0.52129 & 0.60442 \\
\hline$\beta_{3}$ & -0.01905 & -1.12428 & 0.26616 \\
\hline$\beta_{4}$ & 0.01005 & 0.68996 & 0.49335 \\
\hline$\beta_{5}$ & 0.01830 & 0.87160 & 0.38751 \\
\hline$\beta_{6}$ & -0.25896 & -1.45439 & 0.15197 \\
\hline
\end{tabular}


Table 7. Outputs of the OLS regression analysis

\begin{tabular}{|c|c|c|c|}
\hline Coefficients & Value & $\mathbf{t}$ value & $\mathbf{p}$-value \\
\hline $\ln \beta_{0}^{*}$ & 0.93309 & 0.39000 & 0.69847 \\
\hline$\delta_{1}$ & -0.49528 & -1.43300 & 0.15899 \\
\hline$\delta_{2}$ & $\mathbf{0 . 8 7 4 0 7}$ & $\mathbf{2 . 0 5 7 0 0}$ & $\mathbf{0 . 0 4 5 6 6}$ \\
\hline$\delta_{3}$ & 0.07020 & 0.17700 & 0.86014 \\
\hline$\delta_{4}$ & 0.46564 & 1.25400 & 0.21661 \\
\hline$\delta_{5}$ & 0.27801 & 1.26900 & 0.21129 \\
\hline$\delta_{6}$ & -0.08005 & -0.28700 & 0.77557 \\
\hline$\delta_{7}$ & $\mathbf{0 . 6 8 3 9 6}$ & $\mathbf{3 . 5 8 3 0 0}$ & $\mathbf{0 . 0 0 0 8 4}$ \\
\hline$\beta_{1}$ & 0.12153 & 0.47400 & 0.63752 \\
\hline$\beta_{3}$ & $\mathbf{0 . 3 8 5 2 0}$ & $\mathbf{2 . 0 1 7 0 0}$ & $\mathbf{0 . 0 4 9 8 2}$ \\
\hline$\beta_{4}$ & -0.00232 & -0.07100 & 0.94361 \\
\hline$\beta_{5}$ & $\mathbf{0 . 0 7 1 9 4}$ & $\mathbf{2 . 4 2 1 0 0}$ & $\mathbf{0 . 0 1 9 6 8}$ \\
\hline$\beta_{6}$ & -0.02413 & -0.62300 & 0.53630 \\
\hline & 0.9464 & & \\
\hline$R$-square & 0.9306 & & \\
\hline$R$-square adjusted & $1.43 \times 10^{-23}$ & & \\
\hline Overall significance & & & \\
\hline
\end{tabular}

Figure 1. Map of Oman

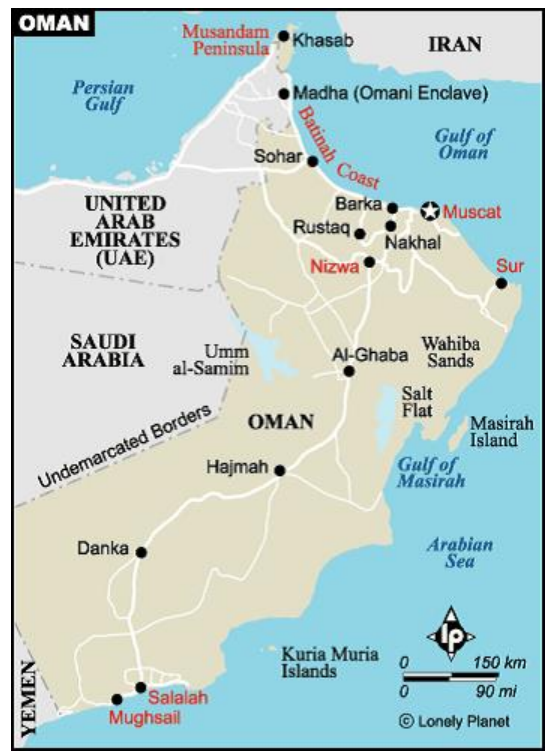

Figure 2. Conceptual model for performance analysis

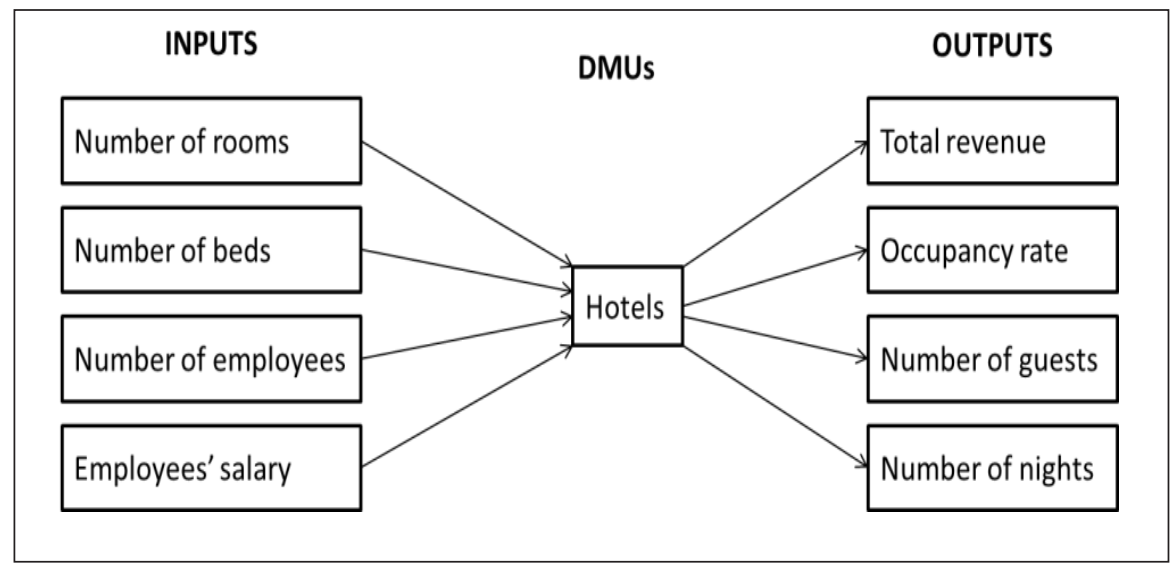

